\title{
SATELLITE REMOTE SENSING OF ECOSYSTEM FUNCTIONS: OPPORTUNITIES AND CHALLENGES FOR REPORTING OBLIGATIONS OF THE EU HABITAT DIRECTIVE
}

\author{
J. Cabello ${ }^{1 *}$, P. Mairota ${ }^{2}$, D. Alcaraz-Segura ${ }^{3}$, S. Arenas-Castro ${ }^{4}$, P. Escribano ${ }^{1}$, P.J. Leitão ${ }^{5,6}$, J. Martínez-López ${ }^{7}$, A. \\ Regos $^{4}$ and J.M. Requena-Mullor ${ }^{1}$
}

${ }^{1)}$ CAESCG/Dept. Biology and Geology, University of Almería, Spain

${ }^{2)}$ Dept. Agro-Environmental and Territorial Sciences, University of Bari, Italy

3) Dept. of Botany, University of Granada, Spain

4) University of Santiago de Compostela \& InBIO/CIBIO, University of Porto, Portugal

${ }^{5)}$ Dept. Landscape Ecology and Environmental System Analysis, Technische Universität Braunschweig, Germany

${ }^{5)}$ Dept. Geography, Humboldt-Universitaet zu Berlin, Germany

${ }^{7)} \mathrm{BC} 3$ - Basque Centre for Climate Change, Spain

*Contact author: jcabello@ual.es

\begin{abstract}
The Habitats Directive (HD) and the associated Natura 2000 Network represent the major commitment of the European Union to biodiversity conservation. They are aimed at maintaining natural habitats in a favourable conservation status, which is assessed every 6 years by the member states under the legal obligation derived from HD Articles 11 and 17. Such assessment relies on habitats compositional and structural attributes, but should also consider ecosystem functions. Monitoring such functions represents an opportunity to incorporate Remote Sensing (RS) into the real-world biodiversity monitoring efforts. Here, we introduce a set of prospects and issues connected with RS aided monitoring of ecosystem functions and services within the framework of the reporting obligations of HD.
\end{abstract}

Keywords: Biodiversity, Conservation status, Habitats, Natura 2000, Management, Remote Sensing.

\section{INTRODUCTION}

The Habitats Directive (HD) (Directive 92/43/EEC) and the associated Natura 2000 Network represent the major response of the European Union to the Convention on Biological Diversity. Its goal is the maintenance of natural habitats in a favourable conservation status (FCS), which is assessed every six years by the member states, under the legal obligation derived from Articles 11 and 17. According to the $\mathrm{HD}$, conservation status is a concept used to emphasize both the habitat extent and the specific structure and functions necessary for long-term maintenance of habitats (Art. 1e). Therefore, its assessment has relied mainly on habitat spatial variation and on habitat compositional and structural attributes such as taxonomic, and structural diversity, occurrence of typical species, as well as on specific environmental parameters such as solar radiation, precipitation, $\mathrm{pH}$ or salinity[1], [2], [3], [4], [5]. However, ecosystem functions are also specifically considered as basic parameters by the HD to evaluate the current conservation status and foreseeable future of habitats (Art. 1e). This is due to their links to biodiversity [6], ecosystem integrity and ecosystem services [7], [8]. Remote Sensing (RS) products and technologies provide indicators on ecosystem functions that could be used to meet reporting obligations of the HD.

\section{OBJeCtIVES}

In this paper, we describe the prospects and issues connected with the RS aided monitoring of ecosystem functions and services within the framework of the HD. The analysis comes from an international workshop on the topic, organised by the University of Almería (October 2017) and supported by the Spanish Ministry of the Environment. The Outcome is a set of considerations about the opportunities and challenges associated with the RS of ecosystem functions to support monitoring and reporting obligations of habitats conservation status arising from the Directive (Article 17 and SCI Data Standard Forms). These considerations are summarised below.

\section{TOWARDS A FUNCTIONAL PERSPECTIVE OF RS TOOLS IN THE} context of The Habitats Directive

\section{A. Opportunities}

Despite the legal obligations for monitoring established by the $\mathrm{HD}$, the incorporation of ecosystem functions indicators to report the conservation status of habitats is hardly being put in practice [9]. This is mainly due to the static view of habitats in the HD, deriving from the definition of the habitats in Annex I of the HD, mainly to fit categories of a phytosociological classification, which was dictated by mapping priorities urged by the need to swiftly implement the Natura 2000 Network. In addition, managers and decision makers lack the most 
up-to-date scientific and technical skills to effectively characterize habitat conservation status.

By providing synoptic information across the Earth and long time series of imagery, RS data and derived products can strongly contribute to reveal and characterize habitat patches close to reference conditions for FCS (at national and regional scales) and to identify evidences and magnitude of spatial and temporal habitats dynamics (threshold conditions). Moreover, $\mathrm{RS}$ of ecosystem function has the potential to clarify the concepts around the biodiversity-ecosystem functioning-ecosystem services paradigm [10], and to provide new relevant technologies, proxies and methodologies to meet with the reporting obligations in the Essential Biological Variables (EBVs) framework [11]. First, the terminology jungle that involves the concepts of ecological process, ecosystem process, ecosystem functions and ecosystem services has been clarified [8]. Second, new sensors and data are continuously being developed [12], and the current off-the shelf RS data product are suitable for assessing diverse ecological and ecosystem processes [13]. Third, a well-established knowledge on proxies to main ecosystem processes driving ecosystem functions is available (e.g. NPP, evapotranspiration, soil respiration, decomposition), currently providing simple but very informative metrics to monitor ecosystem functions e.g. [14], distribution of species and communities [15], and ecosystem services, and protected areas [16]. Finally, methodologies to characterize habitats conservation status [17], [18] and stability [19] are being developed. This information is key to face important challenges posed by the HD, such as preserving habitats in the long term, understanding the likely consequences of climate change scenarios, or focusing management efforts to increase resilience.

\section{B. Limitations and challenges}

Specific ecosystem functions linked to FCS and to be preserved for its maintenance for the long-term, are likely to be habitat-type specific and need to be identified on a case-by-case basis, along with the relevant RS derived proxies. Consequently, while RS derived metrics and products should relate to EBVs, see [8], their application to habitats sensu HD need to be specific for allowing interpretation of their distinctive biodiversity and quantifying the main risks of drifting away from a FCS due to specificities in, e.g. disturbances regimes, climate change vulnerability, land use change, human pressures, and the abandonment of traditional management practices. Inherent case specificity, however does not prevent the definition of transferable (mainly across habitat types and time) of sound remote sensing based approaches [20].

Different sources of variability should be considered to inform on habitats conservation status. Variability in the nature of habitats include the heterogeneity of the criteria adopted for their definition, while most of them are defined according to vegetation composition and physiognomy, others are based on physiographic attributes. In addition, they occur at a wide variety of scales (from small patches to wide landscapes). This requires reconciling ecology vs remote sensing idiosyncratic notions of spatial scales, cf. [21], in order to adopt observation "grains" corresponding to those at which functions occur, at any extent of investigation (from local to regional) [22]. Variability in the assessment goals includes reference conditions (historical records of patches in FCS, historical range of variation), future prospects (trends, stability and thresholds in key processes for the long-term maintenance of habitat). Developing of fit-to-purpose products requires processing/investment of resources.

\section{FROM DATA TO DECISION-MAKING}

Epistemological and technical issues affect the effectiveness and usefulness of the use of RS for managers and decision-makers, here we propose some steps to overcome these issues:

- Strengthen the dialogue between the scientific communities involved in RS and biodiversity conservation, and between them and managers and decision-makers. For this, objects or models to facilitate the integration of needs and constraints of the different parties involved (e.g. data quality, scientific development, legal requirements, concrete problem-solving) [23][24] should probably be designed, and adopting a use-inspired perspective [25].

- Highlight conceptual impacts derived from the science of ecosystem functions on management. These impacts should basically coincide with well-documented scientific messages (i.e. links between ecological processes and ecosystem services) and advances that help to drive a paradigm shift. Sometimes these messages are very well established and obvious to scientists, but their dissemination is very important to connect with managers, decision-makers and society [10] [26].

- Identify instrumental impacts useful to conservation practice and decision-making, through dissemination of successful examples of conservation status and ecosystem services assessment through RS (i.e. an evidence-based approach), and tools to facilitate satellite image processing (e.g. REMOTE [27], Google Earth Engine).

- Explore the synergies and interoperability between products from different sensors, including fusion of optical multispectral and radar data [28].

- Produce indicators to couple with very clear final products for managers. In the case of HD, the evaluation of conservation status should involve a 
system of traffic light signals with three categories (Favourable, Unfavourable-inadequate, and Unfavourable-bad) [18] and encompass several hierarchically nested levels: patch, site, NUTS 2, Member State, and biogeographic region. To each level should correspond a set of indicators according to the ecosystem functions to be monitored, and both the spatial scale and thematic resolution at which the habitat is considered.

- Fostering RS purpose-headed capacity of managers and conservation practitioners [29].

\section{ACKNOWLEDGMents}

TRAGSATEC and the Spanish Ministry of Agriculture and Fisheries, Food and Environment (Contract: "Technical assistance for the analysis of documentation reference and elaboration of technical reports regarding the European symposia on conservation of community interest habitat types focused on the -new biogeographical process- in the Alpine, Atlantic and Mediterranean regions") provided financial support for the workshop. AR was funded by the Xunta de Galicia (post-doctoral fellowship ED481B2016/084-0).

\section{REFERENCES}

[1] S. Lengyel, E. Déri, Z. Varga, R. Horváth, B. Tóthmérész, P-Y. Henry, Kobler, A., L. Kutnar, V. Babij, A. Selinkar, C. Christia, E. Papastergiadou, B. Gruber and K. Henle. Habitat monitoring in Europe: a description of current practices. Biodivers. 574 Conserv. 17, 3327-3339. 2008.

[2] H. Nagendra, R. Lucas, J.P. Honrado, R.H.G. Jongman, C. Tarantino, M. Adamo, P. Mairota. Remote sensing for conservation monitoring: Assessing protected areas, habitat extent, habitat condition, species diversity, and threats. Ecological Indicators. 2012.

[3] A. Lausch, L. Bannehr, M. Beckmann, C. Boehm, H. Feilhauer, J.M. Hacker, M. Heurich, A. Jung, R. Klenke, C. Neumann, M. Pause, D. Rocchini, M.E. Schaepman, S. Schmidtlein, K. Schulz, P. Selsam, J. Settele, A.K. Skidmore, A.F. Corda. Linking Earth Observation and taxonomic, structural and functional biodiversity: Local to ecosystem perspectives. Ecological Indicators, 70, 317-339. 2016.

[4] A. Regos, L. Tapia, A. Gil-Carrera and J. Domínguez. Monitoring protected areas from space: A multi-temporal assessment using raptors as biodiversity surrogates. PLoS ONE 12 (7): e0181769. https://doi.org/10.1371/journal.pone.0181769. 2017.

[5] A. Regos and J. Domínguez. The contribution of Earth observation technologies to the reporting obligations of the Habitats Directive and Natura 2000 network in a protected wetland. PeerJ, 6, e4540. 2018

[6] D. Tilman, F. Isbell and J.M. Cowles. Biodiversity and Ecosystem Functioning. Annual Review of Ecology, Evolution \& Systematics, 45 (1): 471-493. 2014

[7] M Kandizora, B. Burkhard \& F. Müller. 2013. Interactions of ecosystem properties, ecosystem integrity and ecosystem service indicators-A theoretical matrix exercise. Ecological Indicators 28: 54-78.

[8] N. Pettorelli H. Schulte to Bühne, A. Tulloch, G. Dubois, C. Macinnis-Ng, AM Queiros, DA, Keith, M. Wegmann, F. Schrodt, M. Stellmes, R. Sonnenschein, GN. Geller, S. Roy, B. Somers, N. Murray, L. Bland, I. Geijzendorffer, JT. Kerr, S. Broszeit, P.J. Leitão, C. Duncan, G. El Serafy, KS. He, JL. Blanchard, R. Lucas, P. Mairota, TJ. Webb \& E. Nicholson. Satellite remote sensing of ecosystem functions: opportunities, challenges and way forward. Remote Sensing in Ecology and Conservation. doi: 10.1002/rse2.59. 2017.
[9] J. Cabello, T. Pastor and A. Camacho. Thematic group \# 1 - Assessment and sustainable development of ecosystems. Report of the Natura 2000 Biogeographical Seminar Process. Second Mediterranean Seminar. Limassol, Cyprus, 14 to 16 November 2017.

[10] J. Cabello, N. Fernández, D. Alcaraz-Segura, C. Oyonarte, G. Piñeiro, A. Altesor, M. Delibes and JM. Paruelo. The ecosystem functioning dimension in conservation: insights from remote sensing. Biodivers Conserv 21:3287-3305. 2012.

[11] H. M. Pereira, S. Ferrier, M. Walters, G. N. Geller, R. H. G. Jongman, R. J. Scholes, M. W. Bruford, N. Brummitt, S. H. M. Butchart, A. C. Cardoso, N. C. Coops, E. Dulloo, D. P. Faith, J. Freyhof, R. D. Gregory, C. Heip, R. Hoeft, G. Hurtt, W. Jetz, D. S. Karp, M. A. McGeoch, D. Obura, Y. Onoda, N. Pettorelli, B. Reyers, R. Sayre, J. P. W. Scharlemann, S. N. Stuart, E. Turak, M. Walpole, and M. Wegmann. Essential biodiversity variables. Science 339:277-278. 2013.

[12] P. J. Leitão, M. Schwieder, S. Suess, A. Okujeni, L. S. Galvão, S. van der Linden, and P. Hostert. Monitoring natural ecosystem and ecological gradients: perspectives with EnMAP. Remote Sensing 7:13098-13119. 2015.

[13] R. E. Kennedy, S. Andrefouet, W. B. Cohen, C. Gomez, P. Griffiths, M. Hais, S. P. Healey, E. H. Helmer, P. Hostert, M. B. Lyons, G. W. Meigs, D. Pflugmacher, S. R. Phinn, S. L. Powell, P. Scarth, S. Sen, T. A. Schroeder, A. Schneider, R. Sonnenschein, J. E. Vogelmann, M. A. Wulder, and Z. Zhu. Bringing an ecological view of change to Landsat-based remote sensing. Frontiers in Ecology and the Environment 12:339-346. 2014

[14] D. Alcaraz-Segura, J. Cabello, J.M. Paruelo and M. Delibes. Use of descriptors of ecosystem functioning for monitoring a National Park Network: a remote sensing approach. Env. Manag. 43: 38-48. 2009.

[15] P. J. Leitão, M. Schwieder, S. Suess, I. Catry, E. J. Milton, F. Moreira, P. E. Osborne, M. J. Pinto, S. van der Linden, and P. Hostert. Mapping beta diversity from space: sparse generalised dissimilarity modelling (SGDM) for analysing high-dimensional data. Methods in Ecology and Evolution 6:764-771. 2015.

[16] J. Martínez-López, B. Bertzky, FJ. Bonet-García, L. Bastin and G. Dubois. Biophysical Characterization of Protected Areas Globally through Optimized Image Segmentation and Classification. Remote Sensing. 8. (9) 780. doi: 10.3390/rs8090780. 2016.

[17] C. Corbane, S. Lang, Pipkins K, Alleaume S, Deshayes M, García Millán VE, Strasser T, Vanden Borre J, Toon S, MichaelcaIrste F. Remote sensing for mapping natural habitats and their conservation status - New opportunities and challenges. International Journal of Applied Earth Observation and Geoinformation 37: 7-16. 2015.

[18] JM. Requena-Mullor, A. Reyes, P. Escribano and J. Assessment of ecosystem functioning status from space: advancements in the Habitats Directive implementation. Ecological Indicators 89: 893-902. 2018.

[19] P. Escribano, N. Fernández, C. Oyonarte, A. Reyes, JM. Requena and J. Cabello. Resistance and resilience metrics as tools for managers of protected areas. XIV MEDECOS \& XII AEET meeting, Seville, Spain. 31st January-4th February 2017.

[20] J. Vanden Borre, T. Spanhove, B. Haest . Towards a Mature Age of Remote Sensing for Natura 2000 Habitat Conservation: Poor Method Transferability as a Prime Obstacle. In: Díaz-Delgado R., Lucas R., Hurford C. (eds) The Roles of Remote Sensing in Nature Conservation. Springer, Cham. 2017

[21] P. Mairota, B. Cafarelli, RK. Didham, FP. Lovergine, RM. Lucas, H. Nagendra, D. Rocchini and C. Tarantino. Challenges and opportunities in harnessing satellite remote-sensing for biodiversity monitoring. Ecological Informatics, 30 (1): 207-214. 2015.

[22] A. M. Lechner, W. T. Langford, S. A. Bekessy, and S. D. Jones. Are landscape ecologists addressing uncertainty in their remote sensing data? Landscape Ecology 27:1249-1261. 2012.

[23] MD. López-Rodríguez, A. Castro, H. Castro, S. Jorreto and J. Cabello. Science-policy interfaces for addressing environmental problems in arid Spain. Environmental Science and Policy, 50: 1-14. 2015.

[24] S. Star and J. Griesemer. "Institutional Ecology, 'Translations' and Boundary Objects: Amateurs and Professionals in Berkeley's Museum of 
Vertebrate Zoology, 1907-39". Social Studies of Science. 19 (3): 387-420. doi:10.1177/030631289019003001. 1989.

[25] T. U Wall, E. McNie, G. M Garfin. Use-inspired science: making science usable by and useful to decision makers. Front Ecol Environ 2017; 15(10): 551-559, doi:10.1002/fee.1735. 2017.

[26] R. A. Rose, D. Byler, J. R. Eastman, E. Fleishman, G. Geller, S. Goetz, L. Guild, H. Hamilton, M. Hansen, R. Headley, J. Hewson, N. Horning, B. A. Kaplin, N. Laporte, A. Leidner, P. Leimgruber, J. Morisette, J. Musinsky, L. Pintea, A. Prados, V.C. Radeloff, M. Rowen, S. Saatchi, S. Schill, K. Tabor, W. Turner, A.Vodacek, J. Vogelmann, M. Wegmann, D. Wilkie and C. Wilson. Ten ways remote sensing can contribute to conservation. Conservation Biology 29(2): 350-359. 2014.

[27] J. Cabello, D. Alcaraz-Segura, A. Reyes, P. Lourenço, JM. Requena, J. Bonache, P. Castillo, S. Valencia, J. Naya, L. Ramírez and J. Serrada. System for monitoring ecosystem functioning of Network of National
Parks of Spain with remote sensing. Revista de Teledetección 46, 119-131. 2016

[28] H. Schulte to Bühne and N. Pettorelli. Better together: Integrating and fusing multispectral and radar satellite imagery to inform biodiversity monitoring, ecological research and conservation science. Methods Ecol Evol. 00: 1-17. https://doi.org/10.1111/2041-210X.12942. 2017.

[29] I. Palumbo, RA. Rose, RMK. Headley, J. Nackoney, A. Vodacek and M. Wegmann. Building capacity in remote sensing for conservation: present and future challenges. Remote Sensing in Ecology and Conservation, doi: 10.1002/rse2. 2016. 